\title{
Muscarinic Receptor Activity Has Multiple Effects on the Resting Membrane Potentials of CA1 Hippocampal Interneurons
}

\author{
A. Rory McQuiston and Daniel V. Madison \\ Department of Molecular and Cellular Physiology, Stanford University School of Medicine, Stanford, California 94305
}

Inhibitory interneurons appear to be an important target for the muscarinic actions of cholinergic inputs to the hippocampus. We investigated the effect of muscarinic receptor activity on the membrane potential $\left(V_{\mathrm{m}}\right)$ and currents of rat hippocampal CA1 interneurons using whole-cell recording from visually identified CA1 interneurons. The predominant response observed was a muscarinic depolarization that was detected in interneurons from all layers of CA1. This depolarization was mediated by at least two mechanisms: a reduction in a potassium current and a mechanism that depended on extracellular sodium. Other interneurons responded to muscarinic agonists with a hyperpolarization or a biphasic response (hyperpolarization followed by depolarization). Hyperpolarizations and biphasic responses were found in all layers of CA1 but more frequently in stratum radiatum and stratum lacunosum moleculare. Muscarinic hyperpolarization was caused by the activation of a barium- and cesium-sensitive inwardly rectifying potassium channel. A small number of interneurons, primarily in or bordering the stratum pyramidale, produced slow membrane potential $(0.04 \mathrm{~Hz})$ oscillations. Many interneurons did not respond to muscarinic activity at all; half of these were in the stratum oriens. There was no strong correlation between any changes in $V_{m}$ response to muscarine and morphology, as determined by reconstruction of the interneurons. It was not possible to predict the morphology or the layer distribution of an interneuron based on the type of muscarinic membrane potential response it had. This lack of correlation between muscarinic function and morphology implies a greater complexity of interneuron function than has been realized previously.

Key words: acetylcholine; muscarinic receptor; hippocampus; CA1; membrane potential; interneuron
Acetylcholine (ACh) plays an important role in activating cortical regions, including the hippocampus. Synaptic inputs from the medial septal to the hippocampus, including both cholinergic and GABAergic afferents, are essential for a certain type of theta rhythm that has been correlated with attentive behavior (Bland, 1990) and appears to be generated by interneurons (Soltesz and Deschênes, 1993; Ylinen et al., 1995; Tóth et al., 1997). Furthermore, cholinergic dysfunction in the hippocampus has also been described in the pathophysiology of neurodegenerative diseases (Kása et al., 1997). In addition to the well described depletion of cholinergic input to the hippocampus, certain types of muscarinic receptors, e.g., m2, are also downregulated in Alzheimer's disease (Quirion et al., 1989). Interestingly, the $\mathrm{m} 2$ receptor is found on certain types of hippocampal interneurons (Levey et al., 1995; Hájos et al., 1998). The cholinergic projection responsible for these functions may terminate, in part, on interneurons.

Interneurons appear to perform specific and varying functions in the hippocampus (for review, see Freund and Buzsáki, 1996). Specific inhibitory interneurons have been shown to selectively terminate on either pyramidal neurons, cell bodies, axon hillocks (Gulyás et al., 1993a; Buhl et al., 1994; McBain et al., 1994; Sik et al., 1995; Miles et al., 1996), dendrites (Gulyás et al., 1993a,b; Han et al., 1993; Sik et al., 1995; Miles et al., 1996), or other interneu-

\footnotetext{
Received Nov. 30, 1998; revised April 21, 1999; accepted April 28, 1999.

This work was supported by National Institutes of Health Grants MH48874 and MH56454 to D.V.M. We thank Eric Schaible and Paul Pavlidis for writing the acquisition and analysis software and David Prince and John Huguenard for allowing us use of their Neurolucida for neuronal reconstructions.

Correspondence should be addressed to Daniel V. Madison, Beckman Center, Room 111b, Department of Molecular and Cellular Physiology, Stanford University School of Medicine, Stanford, CA 94305-5345.

Copyright (C) 1999 Society for Neuroscience $0270-6474 / 99 / 195693-10 \$ 05.00 / 0$
}

rons exclusively (Acsady et al., 1996; Gulyás et al., 1996; Hájos et al., 1996; Blasco-Ibanez et al., 1998). Thus, subtypes of interneurons may have specific roles in regulating hippocampal functions and may respond differently to muscarinic activity.

Muscarinic receptor activation has been shown to depolarize CA1 pyramidal neurons by the inhibition of a resting potassium channel (Benardo and Prince, 1982; Madison et al., 1987). The effect of muscarinic receptor activity on hippocampal interneurons appears to be more complex and not as well understood. Some CA1 interneurons are depolarized by muscarinic agonists (Benardo and Prince, 1982; Reece and Schwartzkroin, 1991); this leads to an increase in spontaneous GABA inhibitory events measured in pyramidal cells (Pitler and Alger, 1992; Behrends and ten Bruggencate, 1993). More recently, a preliminary study of the effects of muscarinic receptor activity on different interneuron subtypes has shown that, whereas some interneurons are hyperpolarized, others are unaffected (Parra et al., 1998); the ionic bases for these effects were not reported.

In the present study, we investigated in detail the effect of muscarinic receptor activity on the membrane potential $\left(V_{\mathrm{m}}\right)$ of hippocampal interneurons throughout CA1. We describe the physiological effects of muscarinic activity and correlate the anatomy of these interneurons with different types of responses.

\section{MATERIALS AND METHODS}

Male rats (almost all 18- to 25-d-old, but with a few ranging from 16- to 54-d-old) were anesthetized under halothane and killed by decapitation. Their brains were removed and placed in cold, oxygenated saline [(in mM): $\mathrm{NaCl} 119, \mathrm{KCl} 2.5, \mathrm{CaCl}_{2} 1.0, \mathrm{MgCl}_{2} 3, \mathrm{NaHPO}_{4} 1, \mathrm{NaHCO}_{3} 26.2$, glucose 11, and kynurenic acid 1, pH 7.4]. Brains were hemisected, sectioned coronally (300- to 400- $\mu$ m-thick) on a Vibratome (Lancer, Technical Products International, St. Louis, MO), and maintained in 


\begin{tabular}{|c|c|c|c|c|c|}
\hline Layer & Depolarization & Hyperpolarization & Biphasic & No effect & Total \\
\hline SO & 34 & 2 & 6 & 25 & $67(21 \%)$ \\
\hline SP & 9 & 2 & 3 & 4 & $18(6 \%)$ \\
\hline SR & 52 & 29 & 23 & 17 & $121(39 \%)$ \\
\hline SR/SLM & 54 & 20 & 14 & 20 & $108(34 \%)$ \\
\hline All & $149(47 \%)$ & $53(17 \%)$ & $46(15 \%)$ & $66(21 \%)$ & $314(100 \%)$ \\
\hline
\end{tabular}

buffer, first at $30^{\circ} \mathrm{C}(30 \mathrm{~min})$ and then at room temperature $\left(\sim 23^{\circ} \mathrm{C}\right)$; under these conditions, slices were viable for $2-4 \mathrm{hr}$.

For recording, the tissue slice was placed in a recording chamber mounted on the stage of a modified Nikon Optiphot 2 microscope (Technical Instruments, San Francisco, CA). The slice was placed on a cover glass on the bottom of the recording chamber and superfused with aerated room temperature saline [(in mM): $\mathrm{NaCl} 119, \mathrm{KCl} 2.5, \mathrm{CaCl}_{2} 2.5$, $\mathrm{MgSO}_{4} 1.3, \mathrm{NaHPO}_{4} 1, \mathrm{NaHCO}_{3} 26.2$, and glucose 11, pH 7.4]. Slices were visualized using a $40 \times$ water-immersion objective illuminated with near-infrared light. The image was collected by a Hamamatsu C2400 CCD camera (Hamamatsu Corporation, Bridgewater, NJ) with contrast enhancement. The image was displayed on a video monitor, and glass patch pipettes were visually advanced through the slice to the surface of the cell from which to be recorded. Whole-cell patch-clamp recordings were made from visualized interneurons in all layers of area CA1 (MacVicar, 1984; Dodt and Zieglgansberger, 1990).

Patch pipettes were fabricated from borosilicate glass (KG33; $1.5 \mathrm{~mm}$ outer diameter, $1.0 \mathrm{~mm}$ inner diameter; Garner Glass Co., Claremont, CA). The intracellular solution was a gluconate-HEPES buffer [(in mM): $\mathrm{K}$ gluconate $130, \mathrm{NaCl} 8, \mathrm{HEPES} 10, \mathrm{MgATP} 2, \mathrm{Na}_{3} \mathrm{GTP} 0.3$, and BAPTAK $\left._{4} 0.1, \mathrm{pH} 7.25\right]$. When neurobiotin $(0.5 \%)$ was included in the internal solution to label cells, $\mathrm{K}$ gluconate was reduced to $120 \mathrm{mM}$ to maintain osmolarity.

Membrane potentials and/or currents from interneurons were monitored with an Axoclamp 2A amplifier (Axon Instruments, Foster City, CA) acquired through an MIO-1 analog-to-digital interface (National Instruments, Austin, TX) onto a Pentium personal computer (Gateway 2000, North Sioux City, SD) using software written in LabView (National Instruments) by members of our laboratory (Stanford, CA) (Eric Schaible and Paul Pavlidis). Data were analyzed using another program written in LabView and Axum (Mathsoft Inc., Cambridge, MA), a commercially available program. Statistical significance was determined by a two-tailed unpaired Student's $t$ test for data of unequal variance. Values are reported as mean \pm SEM.

Drugs were applied by bath superfusion or by pressure application onto the somata of the cell under investigation via a Picospritzer II (General Valve Corp., Fairfield, NJ). Muscarinic responses were produced by bath application of muscarine, carbachol, or ACh or pressure ejection of ACh. To prevent the activation of nicotinic receptors, the nicotinic antagonists $\alpha$-bungarotoxin $(100 \mathrm{nM})$ or methyllycaconitine (10 $\mathrm{nM})$ and mecamylamine $(10 \mu \mathrm{M})$ were used with carbachol and ACh. For pressure application, $\mathrm{ACh}(100 \mu \mathrm{M})$ was dissolved in a solution similar to the extracellular saline, except that the $\mathrm{NaHCO}_{3}$ was replaced by HEPES (pH 7.4 with $\mathrm{NaOH}$ ).

Cell morphology was visualized by labeling with neurobiotin (Bolam, 1992). For this procedure, slices were fixed overnight in buffered formalin (0.1 M phosphate buffer, $4 \%$ paraformaldehyde, $0.05 \%$ glutaraldehyde, and $0.2 \%$ picric acid), embedded in gelatin, and sectioned $(100 \mu \mathrm{m})$. Sections were permeabilized $(0.5 \%$ Triton $\mathrm{X}-100)$, treated with $0.3 \%$ $\mathrm{H}_{2} \mathrm{O}_{2}$ to reduce background, and incubated overnight in avidin-biotinperoxidase complex (Elite Vectastain ABC kit; Vector Laboratories, Burlingame, CA). Sections were then stained with diaminobenzidine, intensified with nickel, mounted on slides, cleared, and coverslipped. All fills were made in animals between 18 and $25 \mathrm{~d}$ old.

All chemicals were purchased from Fluka (Milwaukee, WI), except for the following: ( \pm )-muscarine, acetylcholine, $\alpha$-bungarotoxin, mecamylamine, and methyllycaconitine (Research Biochemicals, Natick, MA); tetrodotoxin (TTX) (Calbiochem, La Jolla, CA); and paraformaldehyde (Electron Microscopy Sciences, Fort Washington, PA).

\section{RESULTS}

We used whole-cell patch-clamp recording to determine the effect of muscarinic receptor activation on the resting $V_{\mathrm{m}}$ of 314 visually identified interneurons in all layers of rat hippocampal area CA1. We surveyed changes in interneuronal $V_{\mathrm{m}}$, analyzed the ionic mechanisms contributing to changes in $V_{\mathrm{m}}$, and attempted to correlate differences in cell morphology with ionic mechanisms.

\section{Muscarinic receptor activity has multiple effects on the membrane potential of interneurons}

Activation of muscarinic receptors on interneurons of all layers of CA1 showed a variety of responses (Table 1). The majority of interneurons were depolarized (Fig. $1 A$ ) when exposed to muscarinic agonist. Others were hyperpolarized (Fig. $1 B$ ) or displayed a biphasic response (hyperpolarization followed by depolarization) (Fig. 1C) when treated with muscarinic agonists; however, a significant number of interneurons showed no change in $V_{\mathrm{m}}$ (Table 1).

The most common response to muscarinic receptor activation (47\%) (Table 1) was depolarization. This depolarization averaged $\sim 15 \mathrm{mV}$ in amplitude $(+14.5 \pm 0.6 \mathrm{mV} ; n=102 ; p<$ $0.0003 ; z$ test), although this value will presumably vary from cell to cell depending on its resting potential. Two examples are shown in Figure $1 A$. Bath application of carbachol (10 $\mu \mathrm{M})$ (Fig. $1 \mathrm{Ai}$ ) caused a depolarization of sufficient magnitude to cause a barrage of action potentials (APs) that lasted for several minutes. Cells exposed to carbachol for 1-2 min returned to resting $V_{\mathrm{m}}$ only after 20 to $30 \mathrm{~min}$. Hyperpolarizing pulses were used to monitor input resistance of the cell $\left(R_{\mathrm{i}}\right)$. The $R_{\mathrm{i}}$ during the muscarinic depolarization (Fig. $1 A i,-d c$, current was injected to return the $V_{\mathrm{m}}$ to control level) was not different from the $R_{\mathrm{i}}$ preceding carbachol application. Changes in $R_{\mathrm{i}}$ caused by muscarinic depolarizations varied among interneurons; some neurons showed no change in $R_{\mathrm{i}}$, others showed a decrease, and yet others showed an increase. However, when the data were pooled, there was no significant difference in the $R_{\mathrm{i}}$ during depolarization $(-0.8 \pm 2.1 \% ; n=58 ; p>0.65 ; z$ test $)$.

Muscarinic depolarizations could also be produced by brief $(100 \mathrm{msec})$ pressure application of ACh $(100 \mu \mathrm{M})$ directly onto the interneuron cell body (Fig. 1Aii) from a pipette located $\sim 30$ $\mu \mathrm{m}$ away. The depolarization was sufficient to evoke APs (left) and was blocked by the muscarinic receptor antagonist atropine $(1 \mu \mathrm{M} ; n=8)(r i g h t)$. This permitted more rapid responses $(\sim 20$ sec duration) and shorter interapplication intervals $(\sim 2 \mathrm{~min})$ for subsequent drug applications. These muscarinic responses were not inhibited by bath application of TTX $(1 \mu \mathrm{m})$ and/or cadmium $(200 \mu \mathrm{m})(n=5)$, which suggests these effects were the result of the direct action of the muscarinic agonist on the interneurons and not indirectly the result of the release of some other modulator. 
A i

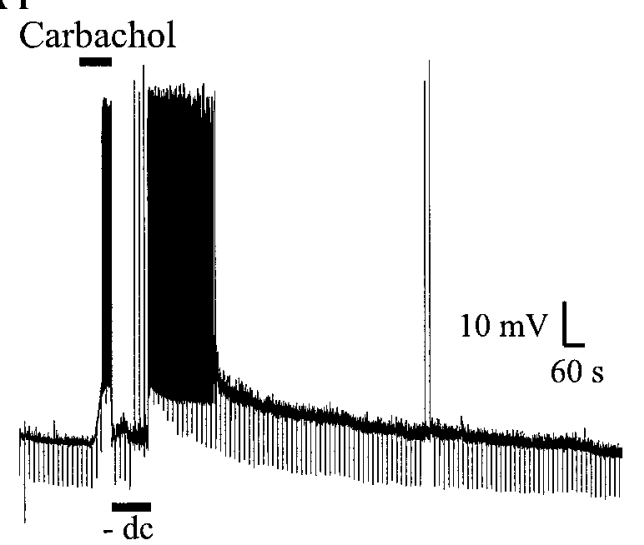

B i

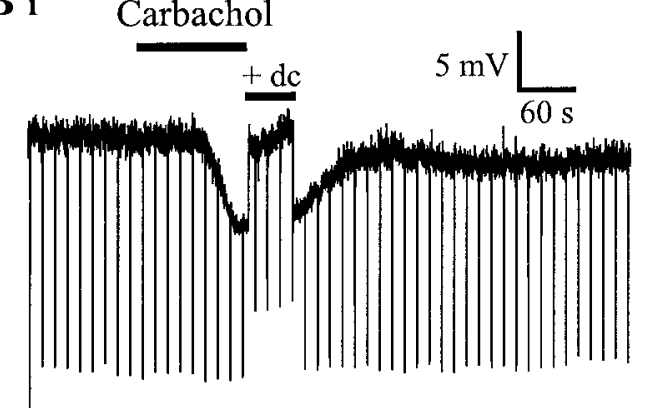

C i Muscarine

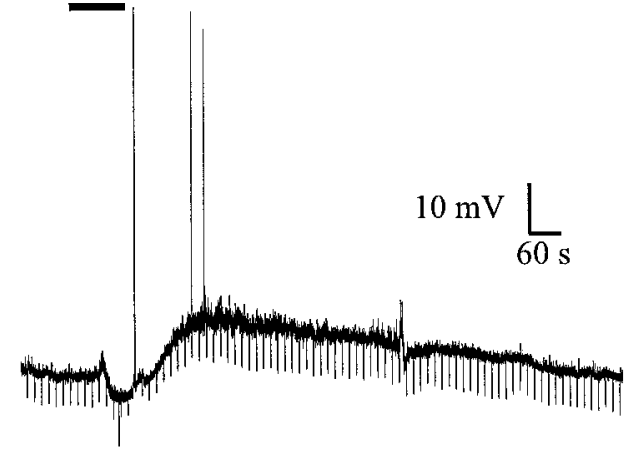

ii

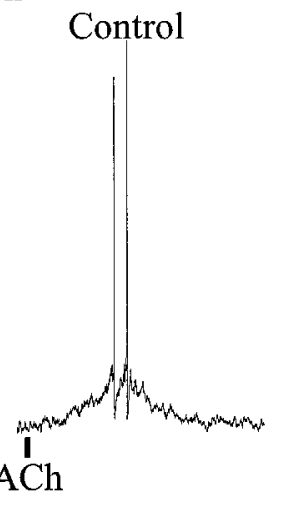

ii

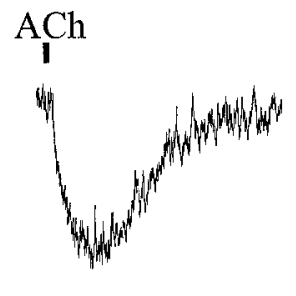

ii

Control

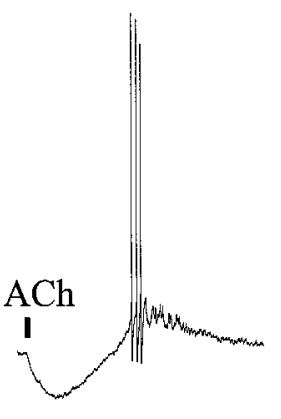

Atropine

$10 \mathrm{mV} \frac{}{5 \mathrm{~s}}$

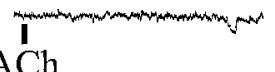

Atropine

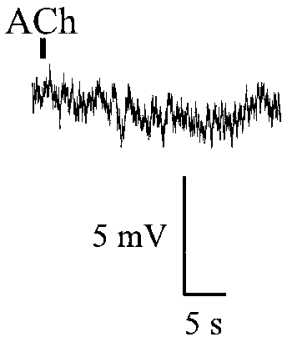

Atropine

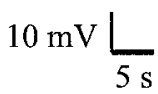

$\mathrm{ACh}$

I

Figure 1. The effects of muscarinic receptor activation on the resting $V_{\mathrm{m}}$ of CA1 interneurons. $A i$, Bath application of carbachol (10 $\left.\mu \mathrm{M}\right)($ bar) caused an interneuron to depolarize. Downward deflections show the $V_{\mathrm{m}}$ response to injections of hyperpolarizing current (20 pA, $\left.600 \mathrm{msec}\right)$ to monitor the $R_{\mathrm{i}}(-d c)$ of the cell. $R_{\mathrm{i}}$ did not appear to change during depolarization. Aii, Pressure application of ACh $(100 \mu \mathrm{M}, 500 \mathrm{msec}, 10 \mathrm{psi}$, in the presence of nicotinic antagonists; bar) onto the cell body caused a brief, delayed depolarization (left) that was blocked by bath application of atropine (1 $\mu \mathrm{M})$ (right). $B i$, Hyperpolarization in response to bath application of carbachol $(10 \mu \mathrm{M})(\mathrm{bar})$. Downward deflections show the $V_{\mathrm{m}}$ response to hyperpolarizing current injection $(600 \mathrm{msec}, 20 \mathrm{pA})$. Notice the decreased $V_{\mathrm{m}}$ response during the hyperpolarization, indicative of a reduction in $R_{\mathrm{i}}$. Bii, Pressure application of ACh (500 msec, $10 \mathrm{psi})$ (bar) onto the cell body of another interneuron caused a rapid hyperpolarization (left) that was blocked by atropine (1 $\mu \mathrm{M})$ (right). $\mathrm{Ci}$, Biphasic response to the application of muscarine $(10 \mu \mathrm{M})$ : a fast brief hyperpolarization followed by a slower longer depolarization. Downward deflections show the response of $V_{\mathrm{m}}$ to hyperpolarizing current injections (600 msec, $20 \mathrm{pA}$ ) to monitor $R_{\mathrm{i}}$. Cii, The response of another interneuron to pressure application of ACh $(100 \mu \mathrm{M}, 10 \mathrm{psi}, 500 \mathrm{msec}$, in the presence of nicotinic antagonists) (bar, left). The cell responded with a large rapid hyperpolarization followed by a depolarization of sufficient amplitude to evoke action potentials. This biphasic response was inhibited by atropine ( $1 \mu \mathrm{M})$ (right).

Another subset of interneurons were hyperpolarized $(17 \%$; $-11.9 \pm 0.6 \mathrm{mV} ; n=53 ; p<0.00003 ; z$ test) (Table 1$)$ by muscarinic receptor activity (Fig. $1 B$, Table 1 ). Bath application of the carbachol caused a hyperpolarization, which was associated with decreased $R_{\mathrm{i}}$ (a smaller $V_{\mathrm{m}}$ response to constant hyperpolarizing current injection) (Fig. $1 B i,+d c$, downward deflections). This was a consistent finding among cells that hyperpolarized $\left(R_{\mathrm{i}}\right.$, $-37.4 \pm 2.8 \% ; n=29 ; p<0.00003 ; z$ test $)$. Direct application of $\mathrm{ACh}(100 \mu \mathrm{M})$ to interneuronal somata caused rapid hyperpolar- izations in some cells (Fig. 1Bii, left). These hyperpolarizations were completely inhibited by the muscarinic antagonist atropine $(n=6)$ (Fig. 1Bii, right). Hyperpolarizations were unaffected by TTX (1 $\mu \mathrm{M} ; n=2)$; this suggests a direct effect of muscarinic agonist on the interneuron cell body rather than an indirect release of another transmitter.

The other common muscarinic response seen in some interneurons was a hyperpolarization followed by a slower depolarization (Fig. 1C). Either bath application of a muscarinic agonist 


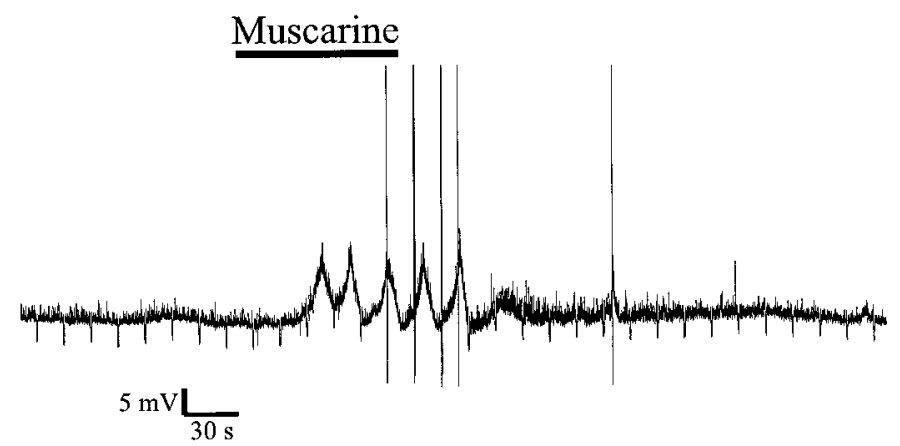

Figure 2. Oscillations in $V_{\mathrm{m}}$ evoked by application of muscarine $(10 \mu \mathrm{M})$ (bar). The oscillations in $V_{\mathrm{m}}$ were of sufficient amplitude to evoke action potentials during the depolarizing phase.

(Fig. 1Ci) or direct application of ACh to the cell body (Fig. 1Cii) could elicit a biphasic $V_{\mathrm{m}}$ response. The biphasic response could be inhibited by atropine ( $1 \mu \mathrm{M} ; n=4)$ (Fig. 1 Cii) but not TTX (1 $\mu \mathrm{M})$ or cadmium $(200 \mu \mathrm{M})(n=4)$. Therefore, the biphasic response was likely the result of the direct activation of muscarinic receptors on the interneuron. The hyperpolarization was invariably associated with a decrease in membrane input resistance, and the input resistance changes accompanying the depo-

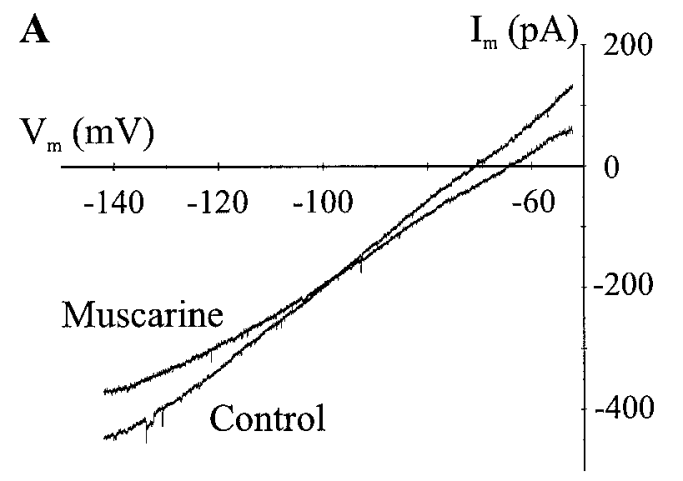

B

larization were mixed because they were with isolated depolarizations. Thus, the hyperpolarization and depolarization of the biphasic response appears to be identical to the corresponding individual responses seen in other interneurons, except for the fact that they were seen together in a single cell.

There was a fourth class of change in $V_{\mathrm{m}}$ after activation of muscarinic receptors that was seen rarely $(n=4)$ and most often in the stratum pyramidale (SP) [two in SP; one in stratum radiatum (SR); and one in SR/stratum lacunosum molecular (SLM)]. These interneurons displayed slow oscillations in $V_{\mathrm{m}}(0.02-0.04$ $\mathrm{Hz}$ ) (Fig. 2) and were not inhibited by TTX (1 $\mu \mathrm{M} ; n=2)$. However, because this response was so infrequent, we did not investigate it further.

\section{Ionic mechanism of muscarinic depolarizations}

We performed ion substitutions and pharmacological manipulations in voltage-clamp experiments in an attempt to uncover the ionic mechanism for muscarinic depolarization. Slow voltage ramps $(2-5 \mathrm{mV} / \mathrm{sec})$ were applied to a voltage-clamped interneuron with and without muscarine $(10 \mu \mathrm{M})$ (Fig. $3 A, B$, top $)$. The current produced by muscarine was determined by plotting the currents produced during the voltage ramp (I-V) (Fig. 3) and subtracting control $I-V$ from muscarine $I-V$ (Fig. $3 A, B$, bottom). Two types of responses were seen. In the first type, the $I-V$

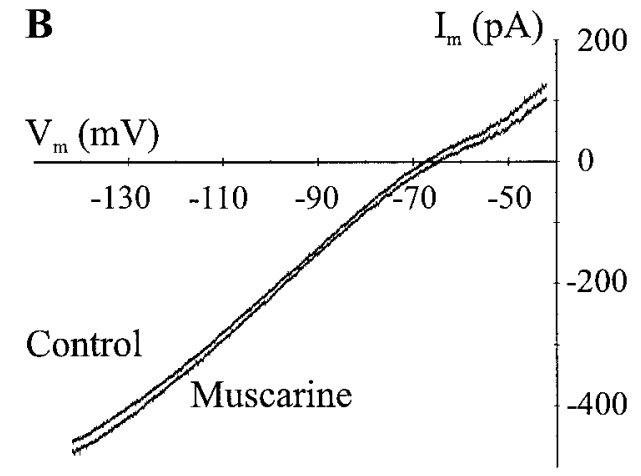

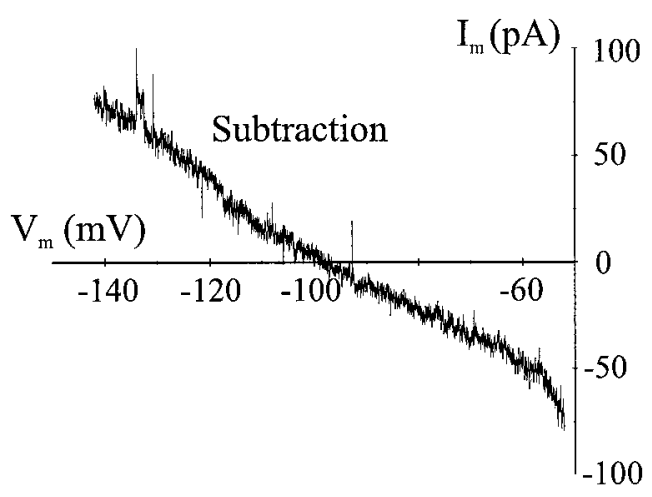

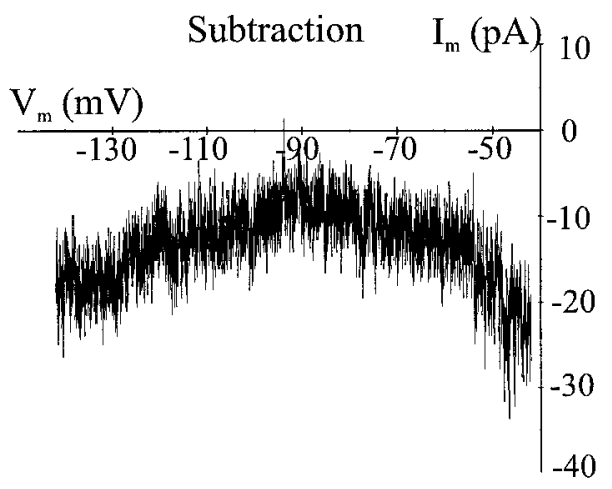

Figure 3. $I-V$ relationships reveal multiple mechanisms for muscarinic membrane depolarizations in interneurons. $I-V$ relationships were constructed for muscarinic responses by performing slow voltage ramps in the absence and presence of muscarinic agonist. Subtraction of the muscarinic $I-V$ from the control $I-V$ yields the current produced by muscarine. Subtracted $I-V \mathrm{~s}$ are shown below the raw $I-V \mathrm{~s}$ in each panel. $A, I-V$ curves in the absence and presence of muscarine $(10 \mu \mathrm{M})$. The $I-V$ relationship for the muscarine response is linear with zero current occurring near the equilibrium potential for potassium $\left(E_{\mathrm{K}},-100.5 \mathrm{mV}\right)$. The muscarinic $I-V$ showed an outward current at $V_{\mathrm{m}}$ values more negative than $E_{\mathrm{K}}$ and inward currents at $V_{\mathrm{m}}$ values more positive that $E_{\mathrm{K}} \cdot B, I-V$ relationship for another interneuron in the absence and presence of muscarine. This interneuron had a muscarinic $I-V$ with a net inward current at all $V_{\mathrm{m}}$ values measured, with no obvious reversal potential for the response. This was the most common pattern seen among muscarine-depolarized interneurons. 
$\mathbf{A}$
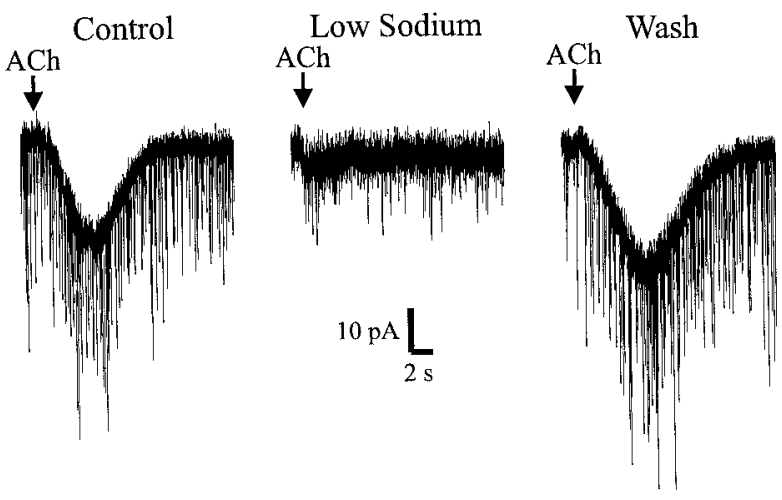

B

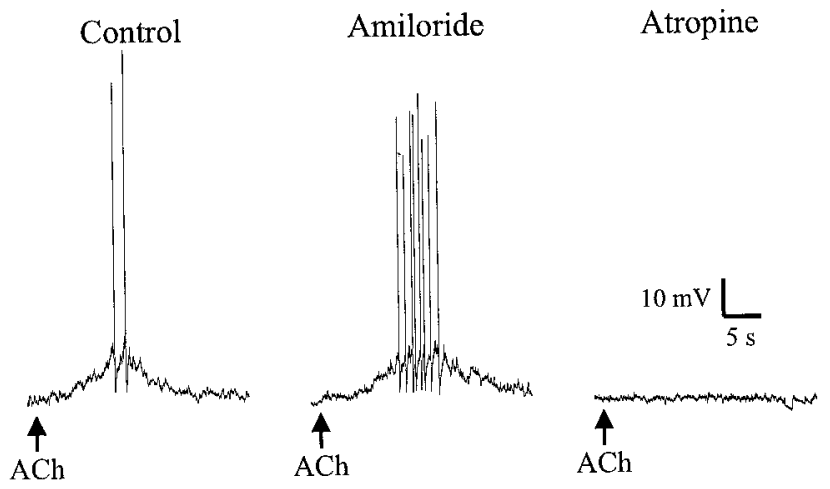

Figure 4. Muscarinic depolarizations require extracellular sodium in most interneurons. $A$, This interneuron was voltage clamped near its resting potential $(-70 \mathrm{mV})$. Pressure injection of ACh $(100 \mu \mathrm{M}, 500 \mathrm{msec}$, $10 \mathrm{psi}$, in nicotinic antagonists) (bar) elicits a slow inward current (left); replacement of extracellular $\mathrm{NaCl}$ with choline chloride inhibits the muscarinic inward current (middle) that recovers after reperfusion with $\mathrm{NaCl}$ (right). The downward deflections in the records are spontaneous glutamatergic EPSCs. B, Pressure application of ACh causes a depolarization of the membrane potential (left) that was not blocked by bath application of amiloride $(100 \mu \mathrm{M})$ (middle) but was inhibited by atropine $(1 \mu \mathrm{M})$ (right).

relationship had a linear negative slope; zero current occurred near the equilibrium potential for potassium $\left(E_{\mathrm{K}},-100.5 \mathrm{mV}\right.$; $E_{\mathrm{rev}},-103.1 \pm 6.1 \mathrm{mV} ; n=8 ; p>0.33 ; z$ test) (Fig. $3 A$, bottom). In the second response, there was a net inward current at all membrane potentials (Fig. 3B, bottom) with no apparent reversal potential $(n=9)$. This suggests that, although some muscarinic depolarizations may be mediated by blockade of a potassium current, others may involve a different mechanism.

We next investigated whether some of the depolarizations involved sodium influx instead of, or in addition to, potassium channel inhibition. In a voltage-clamped interneuron, pressureapplied ACh caused an inward current (Fig. 4A, left). Substitution of extracellular $\mathrm{NaCl}$ by choline chloride inhibited the inward current (Fig. 4A, middle); the inward current recovered after replacement of the $\mathrm{NaCl}$ (Fig. $4 A$, right). Choline substitution inhibited inward currents or depolarizations in a total of 10 cells $(10.1 \pm 3.8 \%$ of control; $p<0.0003 ; z$ test). Sodium transport and some sodium channels are sensitive to amiloride. However, application of amiloride $(100 \mu \mathrm{M})$ to muscarinic depolarizing interneurons did not inhibit the inward current of the depolarization (101 $\pm 4 \%$ of control; $n=6 ; p>0.41 ; n=6$ ) (Fig. 4B). Therefore, we concluded that sodium influx plays a role in perhaps all, but at least a portion, of interneurons depolarized by muscarinic receptor activation.
Muscarinic receptor activation hyperpolarize interneurons by activating an inwardly rectifying potassium channel

We used the same slow voltage-ramp procedure to determine the $I-V$ relationship underlying the ionic mechanism of interneuronal muscarinic hyperpolarizations (Fig. 5Ai). The hyperpolarizing current produced by muscarinic receptor activation had an inwardly rectifying $I-V$ curve and reversed near $E_{\mathrm{K}}(-103 \pm 1.3$ $\mathrm{mV} ; n=3$ ) (Fig. 5Ai). Increasing the extracellular potassium concentration from 2.5 to $10 \mathrm{~mm}$ changed the predicted $E_{\mathrm{K}}$ from -100.5 to $-65.9 \mathrm{mV}$. The muscarinic response $I-V$ relationship continued to be inwardly rectifying and showed zero current near the new $E_{\mathrm{K}}(n=2)$ (Fig. 5Bii). Because the slope of the inwardly rectifying potassium channel current is dependent on the extracellular potassium concentration, we plotted the muscarinic $I-V$ relationship in low and high extracellular potassium on the same scale to determine their relative slopes. The slope of the inward current was greater for higher concentrations of potassium (Fig. $5 C$ ), consistent with the activation of an inwardly rectifying potassium channel.

Both cesium and barium inhibit inwardly rectifying potassium channels to varying degrees. We examined whether cesium (5 $\mathrm{mm})$ or barium $(500 \mu \mathrm{M})$ could inhibit the hyperpolarization produced by muscarinic receptor activation in interneurons. Cesium produced a small reversible inhibition of the muscarinic hyperpolarization ( $63 \pm 9 \%$ of control; $n=8 ; p<0.0003 ; z$ test) (Fig. 6A); however, barium was much more effective at inhibiting the muscarinic hyperpolarization (33.4 $\pm 8.6 \%$ of control; $n=9$; $p<0.0003 ; z$ test) (Fig. 6B). These data are also consistent with the activation of an inwardly rectifying potassium channel.

\section{Localization and morphology of interneuron subtypes with differing muscarinic responses}

Examples of interneurons exhibiting the different muscarinic $V_{\mathrm{m}}$ responses were found in all layers of CA1 (Table 1). The most common response to muscarine observed overall was depolarization, and, not surprisingly, depolarization was the most common response in each layer.

In the stratum oriens (SO), approximately one-third of the neurons were unresponsive to muscarinic agonists, whereas very few were hyperpolarized (3\%) or had biphasic responses (9\%). The majority of cells in SO were depolarized (51\%). Similar findings were observed in the SP; the majority were depolarized $(50 \%), 22 \%$ showed no effect, $11 \%$ were hyperpolarized, and $17 \%$ were biphasic. The frequency of hyperpolarizing and biphasic response interneurons increased in the SR (24\% hyperpolarized, 19\% biphasic) and SLM (including the border with SR, SR/SLM; $18 \%$ hyperpolarized, $13 \%$ biphasic). Together, the cells in the SR and SR/SLM accounted for $92 \%$ of the interneurons, showing a hyperpolarizing response to muscarine, and $80 \%$ of the cells, showing a biphasic response. However, depolarization was still the most common response in SR and SR/SLM (43\% and 50\%, respectively). Approximately $15 \%$ of the cells in these layers were unresponsive to muscarine (SR, 14\%; SR/SLM, $18 \%)$.

In the hippocampus, interneurons with particular presumed functions are generally not confined to particular layers of CA1. The presumed function of a particular interneuron is most often discerned from its axonal and dendritic arborization pattern. Thus, we attempted to determine whether the interneurons that display particular $V_{\mathrm{m}}$ responses to muscarine fell into specific types based on morphology. To do this, we analyzed the inter- 
A i

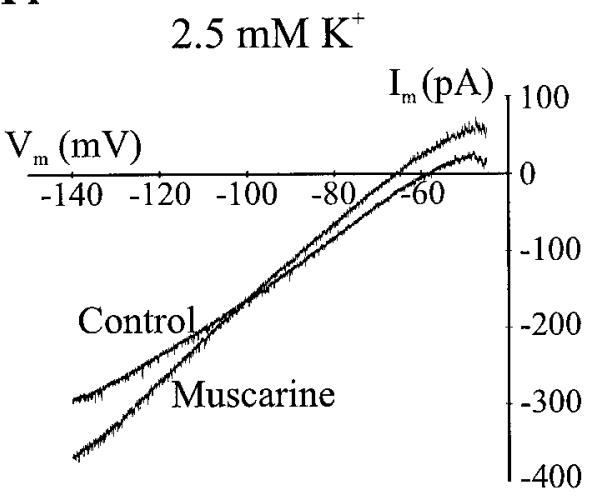

ii

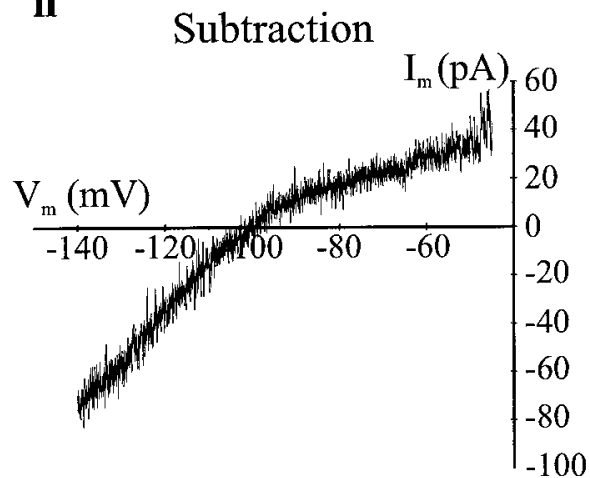

B i
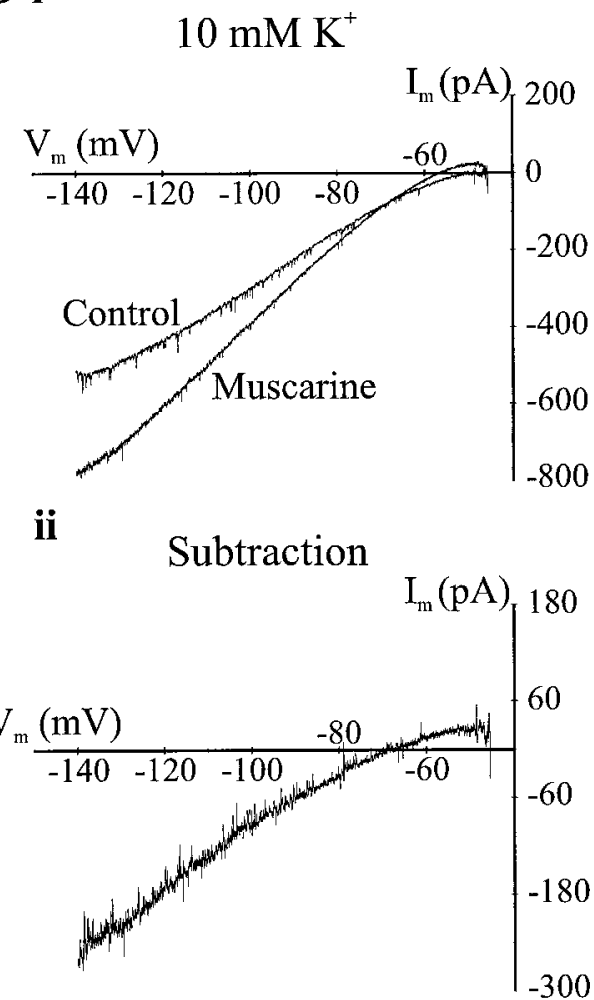

\section{Subtraction Overlay}

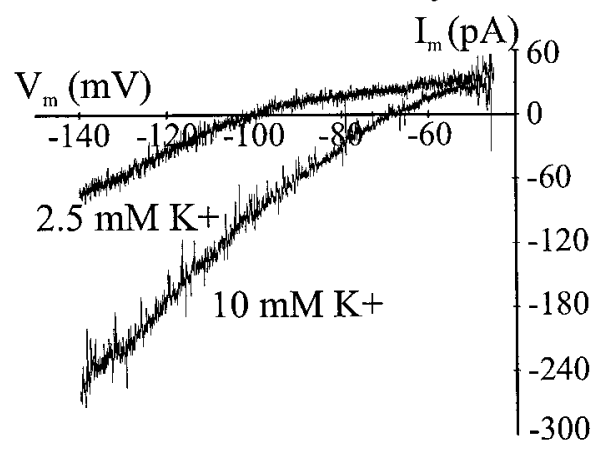

Figure 5. Muscarinic receptor activity hyperpolarize some interneurons via the activation of inwardly rectifying potassium channels. $A i$, In normal extracellular potassium, a slow voltage ramp showed that the $I-V$ relationship of the cell changes with bath perfusion of muscarine (10 $\mu \mathrm{M}$ ). Aii, Subtracting control $I-V$ curve from the muscarinic $I-V$ curve gives the muscarinic current; this current rectifies inwardly with zero current near the equilibrium potential for potassium $\left(E_{\mathrm{K}},-100.5 \mathrm{mV}\right)$. The muscarinic current is inward for potentials more negative than $E_{\mathrm{K}}$ and outward for $V_{\mathrm{m}}$ values more positive than $E_{\mathrm{K}}$. Bi, Raising the extracellular potassium in the cell from 2.5 to $10 \mathrm{~mm}$ (in $A$ ) changes the $I-V$ relationships in both control (saline) and muscarine. Bii, Subtraction of the control $I-V$ from the muscarinic $I-V$ indicates that the muscarinic current has changed its reversal potential to near the new $E_{\mathrm{K}}\left(E_{\mathrm{rev}},-72.1 \mathrm{mV}\right)$. The muscarinic current in high potassium was still inwardly rectifying. $C$, Graph of the muscarinic $I-V$ responses at two concentrations of extracellular potassium $(2.5$ and $10 \mathrm{mM})$. Increased potassium increases the slope of the negative current.

neurons by labeling them intracellularly with neurobiotin and reconstructing their axonal and dendritic arbors by Neurolucida. We found no obvious relationship between morphology and response to muscarine. Some depolarizing interneurons had dendrites in all layers (Fig. $7 A, B$ ), whereas others were confined to one particular layer (Fig. $7 C$ ). Some depolarizing interneurons had axons innervating the pyramidal cell body layer (Figs. $7 A$, $8 A$ ), whereas others innervated the pyramidal cell dendritic layers (SO, SR, SLM) (Figs. 7B, 8C). The axonal and dendritic processes of hyperpolarizing and biphasic-response interneurons were found throughout all layers of area CA1 (Fig. 7C,D, respectively). However, we did find that interneurons with similar mor- phologies could and did have different responses to muscarinic receptor activation. For example, in Figure 8, although the interneurons in $A$ and $B$ have similar morphologies (cell bodies near the SO/SP border, dendrites spanning most layers, and axons confined to the pyramidal cell body layer), one was depolarized by muscarine (Fig. $8 A$ ), whereas the other one was unaffected (Fig. 8B). Similarly, in Figure 8, the neurons in $C$ and $D$ were morphologically similar; however, the neuron in $C$ was depolarized, whereas the neuron in $D$ showed no change in $V_{\mathrm{m}}$. For interneurons innervating both the apical and basal dendrites of pyramidal cells (bistratified cells), six of eight depolarized, one was biphasic, and another did not respond. 

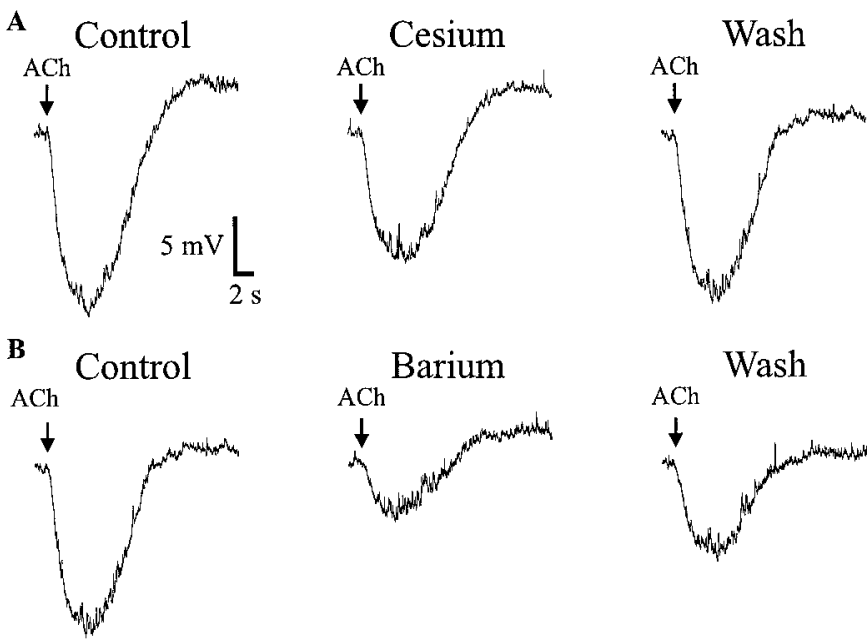

Figure 6. Muscarinic hyperpolarizations are partially inhibited by cesium and barium. A, Pressure application of ACh (100 $\mu \mathrm{M}, 500 \mathrm{msec}, 10$ psi, in nicotinic antagonists) elicited a fast hyperpolarization (left). Extracellular cesium $(5 \mathrm{~mm})$ partially inhibited the muscarinic hyperpolarization (middle), which recovered after removal of cesium (right). B, Same cell as in $A$. Hyperpolarization (left) is significantly inhibited by barium $(500 \mu \mathrm{M})$ (bath application) (middle), which recovers after removal of barium from the bath (right).

There was also no correlation between response to muscarine and axonal projection and termination; of six neurons whose axons we classified as perisomatic, three were depolarized, one oscillated, and the other two showed no response. Of cells that projected to SLM from SO, two of four cells had small depolarizations, whereas the other two did not respond. Of 11 cells that ramified mainly in SR, eight depolarized, one did not respond, one hyperpolarized, and one was biphasic. We studied five cells with axons that ramified in SR and SLM: three of the five depolarized, one hyperpolarized, and one showed no effect. Interestingly, of six cells with axons that innervated all layers, only one depolarized, two hyperpolarized, one was biphasic, and two did not respond. These data allowed us to conclude only that interneurons that had hyperpolarizing or biphasic responses appeared to have wide ranging axonal patterns of innervation, much of it in SR but spanning more than one layer. Cells that depolarized in response to muscarinic receptor activation fell into no distinct morphological type.

\section{DISCUSSION}

In this study, we have demonstrated that muscarinic receptor activation has a variety of effects on area CA1 interneurons. In all, five possible outcomes were observed. Interneurons could respond to a muscarinic agonist by depolarization, hyperpolarization, hyperpolarization followed by a slower depolarization (biphasic), an oscillation, or show no response. We could not definitively correlate type of response with the layer in which the cell body was found or with any characteristics of axonal or dendritic morphology. Our data suggest that the function of an interneuron cannot, at least with regard to its muscarinic function, be deduced from its anatomical structure alone. Interneurons with apparently similar morphology may serve to modulate the hippocampal circuitry differently when under muscarinic influence.

\section{Interneurons depolarized by muscarinic receptor activation}

Depolarization was the most frequent response to muscarinic receptor activation. This confirms direct and indirect measurements, which demonstrated that some interneurons are depolarized by muscarinic receptor activation (Benardo and Prince, 1982; Reece and Schwartzkroin, 1991; Pitler and Alger, 1992; Behrends and ten Bruggencate, 1993; Parra et al., 1998). These cells were found in all layers of CA1 and did not appear to fall into a particular anatomical class of interneuron, in agreement with a recent study (Parra et al., 1998). Depolarization was a complex response, likely involving more than one mechanism. Generally, depolarization was not accompanied by a concomitant change in the $R_{\mathrm{i}}$. Furthermore, voltage-ramp experiments showed two types of $I-V$ relationships for muscarinic-induced depolarization. In some cells, muscarinic receptor activation produced a linear $I-V$ relationship in a negative voltage range, with a negative slope that reversed at the $E_{\mathrm{K}}$; this is consistent with the inhibition of a voltage-independent leakage potassium current as seen in pyramidal neurons (Madison et al., 1987). However, the limited voltage range over which we were able to examine this current does not allow us to rule out voltage-dependent potassium currents, including calcium-activated currents promoted by calcium release from intracellular stores. Most depolarizing interneurons showed a net inward current at all $V_{\mathrm{m}}$ values with no reversal potential, similar to muscarinic depolarization in rat locus ceruleus neurons (LC) and guinea pig hippocampal pyramidal neurons (Benson et al., 1988; Shen and North, 1992). In both these preparations, there was no change in the input resistance of the cell, and the muscarinic $I-V$ relationship produced a net inward current with no reversal potential. These authors suggested that muscarinic depolarizations were caused by the simultaneous inhibition of resting potassium channels and the activation of a voltage-independent nonselective cation current. The contributions of both channel types canceled out the effects of each other on the $R_{\mathrm{i}}$ of the cell, thereby producing a depolarization without reversal or any net change in $R_{\mathrm{i}}$. Furthermore, the muscarinic inward current was suppressed by low extracellular sodium as was described for LC neurons (Shen and North, 1992).

Another factor that could contribute to this inward current is a brain ENaC (epithelial sodium channel) (Garty and Palmer, 1997). These channels are usually found in epithelial cells and are sensitive to low concentrations of amiloride. However, amiloride did not appear to inhibit the muscarinic depolarization at sufficient concentrations to block these channels (Garty and Palmer, 1997). Muscarine could also exert its effect by activating an electrogenic transporter. The concentrations of muscarine agonist used in our experiments were too low to block the brain sodium-calcium exchanger (Schellenberg et al., 1983), so the activation of a muscarinic-sensitive electrogenic pump cannot be ruled out. We believe it is most likely that muscarinic depolarization is a result of the simultaneous inhibition of a potassium channel and the activation of a cation current. In agreement with this hypothesis, some interneurons appear to use potassium channel inhibition as the primary mechanism for depolarization, similarly to LC and pyramidal neurons (Benson et al., 1988; Shen and North, 1992).

\section{Hyperpolarizing interneurons}

Like depolarizing interneurons, hyperpolarizing interneurons were found in all layers of CA1 and did not comprise a morphologically distinct population, consistent with the findings of a 
A

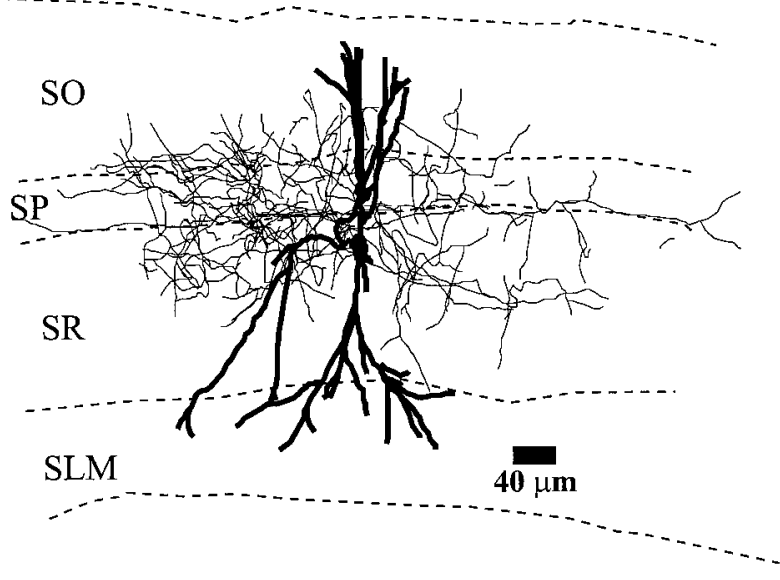

B

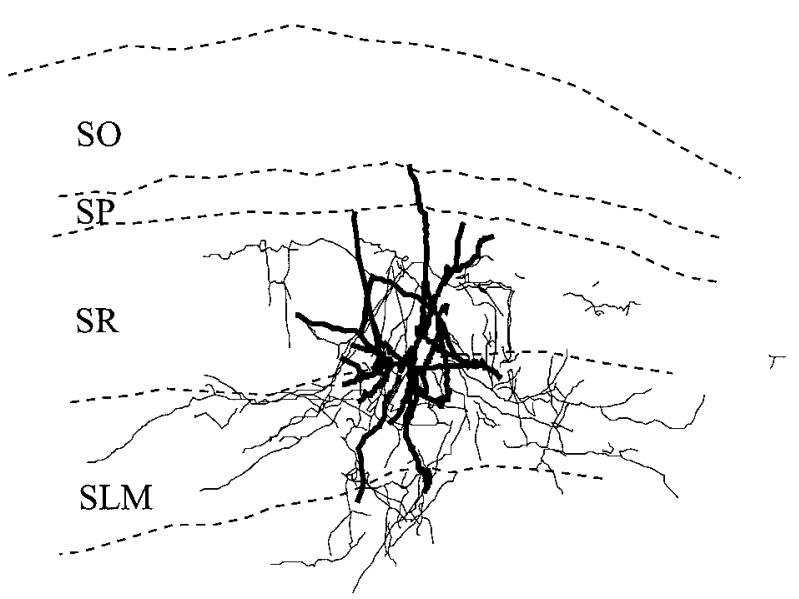

C

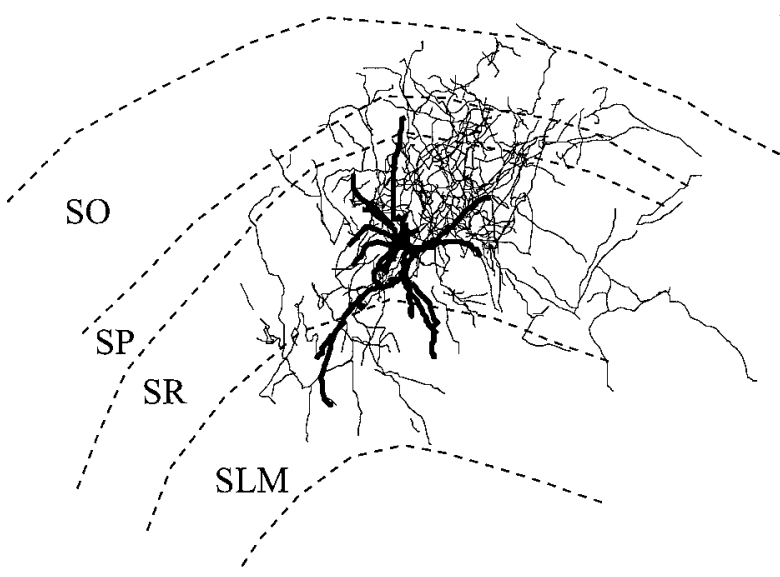

D

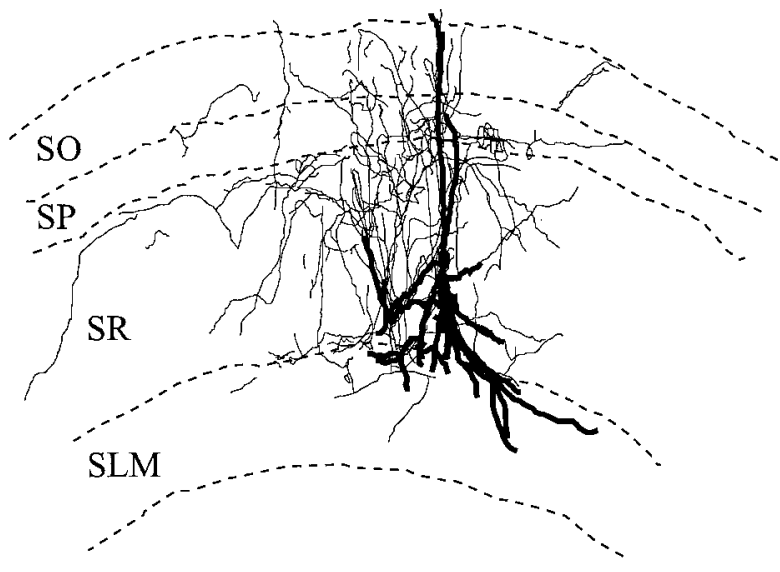

Figure 7. Morphology of interneurons with different membrane potential responses to muscarinic agonists. $A, B$, Interneurons with depolarizing responses to muscarinic receptor activation. $A$, An interneuron whose axons projected into the pyramidal cell body. $B$, An interneuron whose axon avoided the pyramidal cell layer. $C$, Morphology of an interneuron that showed a biphasic response. These interneurons and those hyperpolarized by muscarinic receptor activation showed varying morphologies with axons projecting to all layers of CA1.

recent study (Parra et al., 1998). The frequency of encountering hyperpolarizing interneurons was greater in SR and SLM. The one common morphological characteristic of these neurons that we could discern was their widely dispersed axons, which ramified throughout multiple layers of CA1.

Muscarinic hyperpolarization was accompanied by a consistent decrease in $R_{\mathrm{i}}$. The properties of the muscarinic hyperpolarizing current were similar to those of an inwardly rectifying potassium channel (Nichols and Lopatin, 1997). The $I-V$ relationship of the muscarinic response was that of a current that reversed near the $E_{\mathrm{K}}$ and passed more inward than outward current. Changing the extracellular potassium concentration altered the reversal potential, and the slope of the inward current curve increased with increasing extracellular potassium. Hyperpolarization was sensitive to extracellular barium and less sensitive to extracellular cesium, which is also consistent with the activation of an inward rectifier. Thus, muscarinic receptor stimulation activates an inwardly rectifying potassium channel in an as yet unidentified subpopulation of interneurons.

\section{Interneurons with biphasic responses}

Interneurons with biphasic responses have not been described previously. Like the hyperpolarizing interneurons, interneurons with biphasic responses were found in all layers of CA1 but most often in SR and SLM. Although the biphasic cells did not have a distinct morphology and did not appear to constitute a functionally distinct subgroup, the axons of these neurons often branched extensively through several layers. The hyperpolarizing phase of the biphasic muscarinic response was similar to that shown by neurons that responded only with hyperpolarization as to was accompanied by an increase in potassium conductance. The depolarizing phase of the biphasic response was also similar to that seen in interneurons showing only the depolarizing response. The conductance change underlying the depolarizing phase of the biphasic response could be an increase or a decrease in input resistance, or there could be no apparent net change. Thus, the response in these interneurons appears to vary only in that both responses are seen in the same interneuron.

\section{Interneurons with muscarinic slow oscillations}

A subpopulation of interneurons produced slow membrane oscillations when exposed to muscarinic agonists. This type of response has not been described previously. Oscillations were observed in only four cells; half of these were found in the SP. These large-amplitude oscillations were slow, 0.02-0.06 Hz, and fell outside the frequency range of known behaviorally relevant circuit oscillation frequency (Freund and Buzsáki, 1996). However, this could be attributable to the low temperatures at which the experiments were performed and the slow method by which the agonists were applied. Further experiments are required to de- 
A

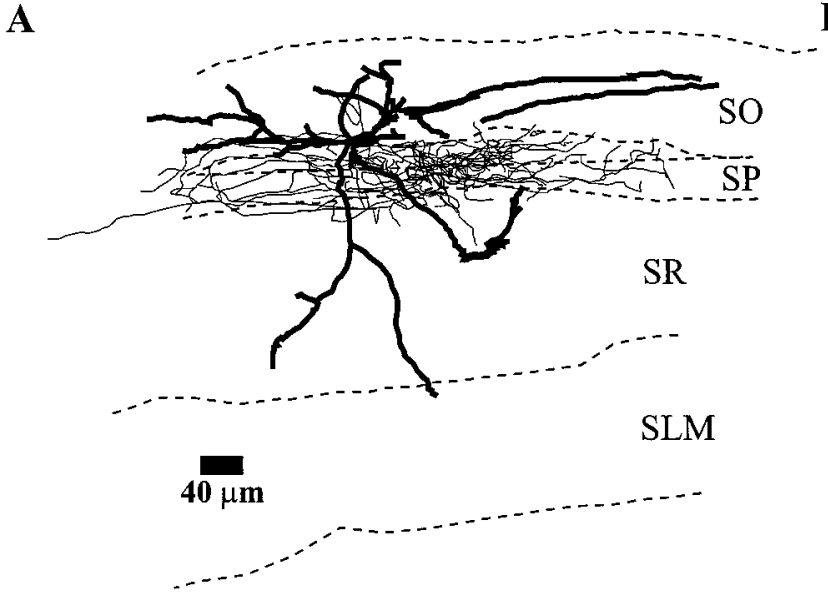

B

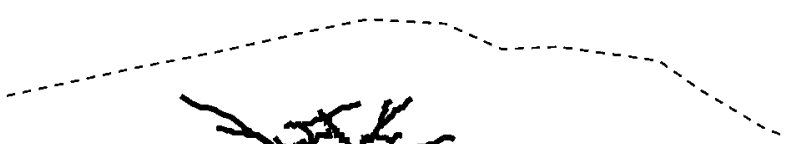

SO
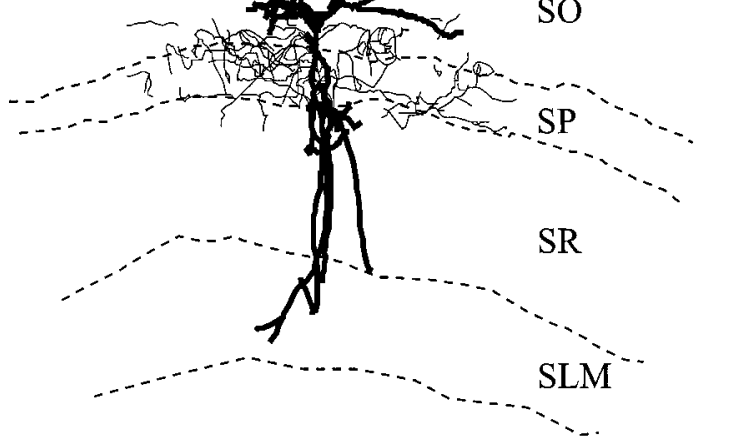

D

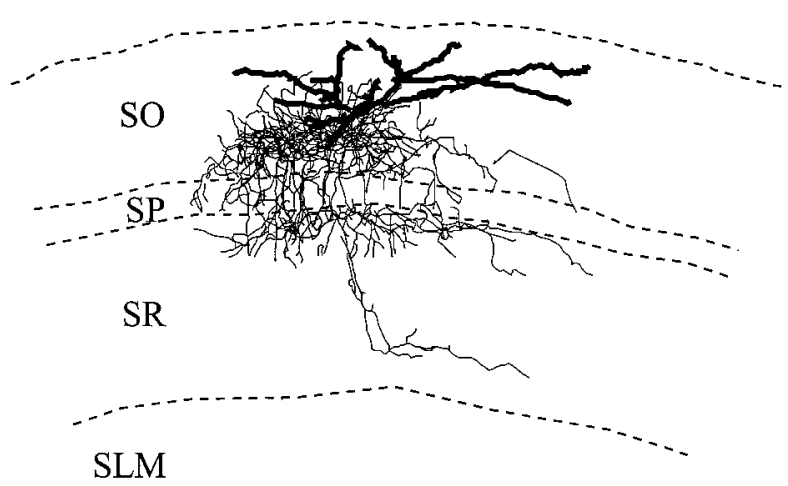

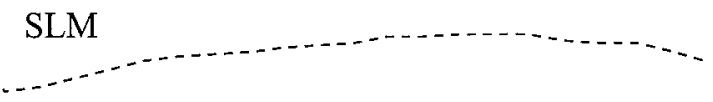

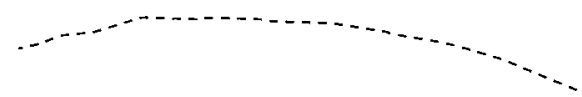

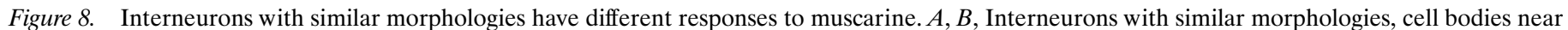

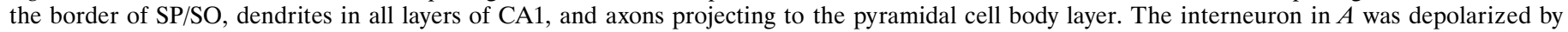

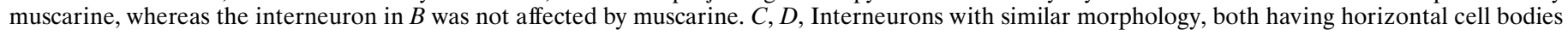

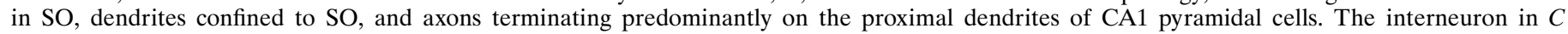
responded to muscarinic receptor activity with a depolarization, whereas the neuron in $D$ showed no change in membrane potential.

termine whether muscarinic receptor activity can cause particular interneurons to oscillate at higher frequencies, as has been reported for metabotropic glutamate receptors (Whittington et al., 1995).

A significant number of interneurons did not respond to muscarinic receptor activation. Nonresponding interneurons were found in all layers, most frequently in SO. Morphologically, there was no way to identify a nonresponding cell, and the morphology of some nonresponding cells was apparently similar to that of responding cells.

\section{Physiological relevance of muscarinic membrane responses}

Our observations that hippocampal interneurons respond in a variety of ways to muscarinic receptor activation reinforces the idea of the complexity of interneuronal function compared with that of the uniform principal cells (Freund and Buzsáki, 1996). Previously, interneurons have been classified into distinct anatomical and functional classes (Freund and Buzsáki, 1996). They have been shown to terminate on different parts of the pyramidal neuron, soma, or dendrites (Gulyás et al., 1993a,b; Han et al., 1993; Buhl et al., 1994; McBain et al., 1994; Sik et al., 1995) to inhibit specific electrical activity in pyramidal cells (Miles et al.,
1996) and to release different peptide cotransmitters along with GABA (Freund and Buzsáki, 1996). Furthermore, there are interneurons that selectively innervate other interneurons (Acsady et al., 1996; Gulyás et al., 1996; Hájos et al., 1996; Blasco-Ibanez et al., 1998). A recent study has shown that different interneurons contain different combinations of multiple neuromodulators, and these combinations may be functionally significant (Parra et al., 1998). Our data confirm and extend these findings for muscarinic modulation of interneurons. Our observation that interneurons with similar morphologies can have different responses to muscarine suggests that interneurons with similar inputs and outputs may not be all of one functional class. Instead, they may serve different functions in the hippocampal circuit for reasons and by mechanisms that are not apparent from their morphology alone. One caveat to this may be the age of the animals used in this study. To facilitate the acquisition of whole-cell recordings, the animals in which physiology and anatomy were compared were between 18 and $25 \mathrm{~d}$ of age. Further differentiation of interneurons after that age could, in theory, provide some anatomical features that do correlate with muscarinic responsiveness. The finding that interneurons with different morphologies can have the same response to muscarine suggests that distribution of 
muscarinic responsiveness may be an important feature of the inhibitory circuitry. These results together certainly suggest a complexity to the classification of interneuronal function that heretofore may not have been fully realized.

\section{REFERENCES}

Acsady L, Gorcs TJ, Freund TF (1996) Different populations of vasoactive intestinal polypeptide-immunoreactive interneurons are specialized to control pyramidal cells or interneurons in the hippocampus. Neuroscience 73:317-334.

Behrends JC, ten Bruggencate G (1993) Cholinergic modulation of synaptic inhibition in the guinea pig hippocampus in vitro: excitation of GABAergic interneurons and inhibition of GABA release. J Neurophysiol 69:626-629.

Benardo LS, Prince DA (1982) Cholinergic excitation of mammalian hippocampal pyramidal cells. Brain Res 249:315-331.

Benson DM, Blitzer RD, Landau EM (1988) An analysis of the depolarization produced in guinea-pig hippocampus by cholinergic receptor stimulation. J Physiol (Lond) 404:479-496.

Bland BH (1990) Physiology and pharmacology of hippocampal formation theta rhythms. Prog Neurobiol 26:1-54.

Blasco-Ibanez JM, Martinez-Guijarro FJ, Freund TF (1998) Enkephalin-containing interneurons are specialized to innervate other interneurons in the hippocampal CA1 region of the rat and guinea-pig. Eur J Neurosci 10:1784-1795.

Bolam JP (1992) Experimental neuroanatomy: a practical approach. Oxford: Oxford UP.

Buhl EH, Halasy K, Somogyi P (1994) Diverse sources of hippocampal unitary inhibitory postsynaptic potentials and the number of synaptic release sites. Nature 368:823-828.

Dodt HU, Zieglgansberger W (1990) Visualizing unstained neurons in living brain slices by infrared DIC-videomicroscopy. Brain Res 537:333-336

Freund TF, Buzsáki G (1996) Interneurons of the hippocampus. Hippocampus 6:347-470.

Garty H, Palmer LG (1997) Epithelial sodium channels: function, structure, and regulation. Physiol Rev 77:359-396.

Gulyás AI, Freund TF (1996) Pyramidal cell dendrites are the primary targets of calbindin D28k-immunoreactive interneurons in the hippocampus. Hippocampus 6:525-534.

Gulyás AI, Miles R, Hájos N, Freund TF (1993a) Precision and variability in postsynaptic target selection of inhibitory cells in the hippocampal CA3 region. Eur J Neurosci 5:1729-1751.

Gulyás AI, Miles R, Sik A, Toth K, Tamamaki N, Freund TF (1993b) Hippocampal pyramidal cells excite inhibitory neurons through a single release site. Nature 366:683-687.

Gulyás AI, Hajos N, Freund TF (1996) Interneurons containing calretinin are specialized to control other interneurons in the rat hippocampus. J Neurosci 16:3397-3411.

Hájos N, Acsady L, Freund TF (1996) Target selectivity and neurochemical characteristics of VIP-immunoreactive interneurons in the rat dentate gyrus. Eur J Neurosci 8:1415-1431.

Hájos N, Papp EC, Acsády L, Levey AI, Freund TF (1998) Distinct interneuron types express $\mathrm{m} 2$ muscarinic receptor immunoreactivity on their dendrites or axon terminals in the hippocampus. Neuroscience 82:355-376.
Han ZS, Buhl EH, Lorinczi Z, Somogyi P (1993) A high degree of spatial selectivity in the axonal and dendritic domains of physiologically identified local-circuit neurons in the dentate gyrus of the rat hippocampus. Eur J Neurosci 5:395-410.

Kása P, Rakonczay Z, Gulya K (1997) The cholinergic system in Alzheimer's disease. Prog Neurobiol 52:511-535.

Levey AI, Edmunds SM, Koliatsos V, Wiley RG, Heilman CJ (1995) Expression of $\mathrm{m} 1-\mathrm{m} 4$ muscarinic acetylcholine receptor proteins in rat hippocampus and regulation by cholinergic innervation. J Neurosci 15:4077-4092.

MacVicar BA (1984) Infrared video microscopy to visualize neurons in the in vitro brain slice preparation. J Neurosci Methods 12:133-139.

Madison DV, Lancaster B, Nicoll RA (1987) Voltage-clamp analysis of cholinergic action in the hippocampus. J Neurosci 7:733-741.

McBain CJ, DiChiara TJ, Kauer JA (1994) Activation of metabotropic glutamate receptors differentially affects two classes of hippocampal interneurons and potentiates excitatory synaptic transmission. J Neurosci 14:4433-4445.

Miles R, Tóth K, Gulyás AI, Hájos N, Freund TF (1996) Differences between somatic and dendritic inhibition in the hippocampus. Neuron 16:815-823.

Nichols CG, Lopatin AN (1997) Inward rectifier potassium channels. Ann Rev Physiol 59:171-191.

Parra P, Gulyás AI, Miles, R (1998) How many subtypes of inhibitory cells in the hippocampus? Neuron 20:983-993.

Pitler TA, Alger BE (1992) Cholinergic excitation of GABAergic interneurons in the rat hippocampal slice. J Physiol (Lond) 450:127-142.

Quirion R, Aubert I, Lapchak PA, Schaum RP, Teolis S, Gauthier S, Araujo DM (1989) Muscarinic receptor subtypes in human neurodegenerative disorders: focus on Alzheimer's disease. Trends Pharmacol Sci Suppl:80-84.

Reece LJ, Schwartzkroin PA (1991) Effects of cholinergic agonists on two non-pyramidal cell types in rat hippocampal slices. Brain Res 566:115-126.

Schellenberg GD, Anderson L, Swanson PD (1983) Inhibition of $\mathrm{Na}^{+}-$ $\mathrm{Ca}^{2+}$ exchange in rat brain by amiloride. Mol Pharmacol 24:251-258.

Shen KZ, North RA (1992) Muscarine increases cation conductance and decreases potassium conductance in rat locus coeruleus neurones. J Physiol (Lond) 455:471-485.

Sik A, Penttonen M, Ylinen A, Buzsáki G (1995) Hippocampal CA1 interneurons: an in vivo intracellular labeling study. J Neurosci 15:6651-6665.

Soltesz I, Deschênes M (1993) Low- and high-frequency membrane potential oscillations during theta activity in CA1 and CA3 pyramidal neurons of the rat hippocampus under ketamine-xylazine anesthesia. J Neurophysiol 70:97-116.

Tóth K, Freund TF, Miles R (1997) Disinhibition of rat hippocampal pyramidal cells by GABAergic afferents from the septum. J Physiol (Lond) 500:463-474.

Whittington MA, Traub RD, Jefferys JG (1995) Synchronized oscillations in interneuron networks driven by metabotropic glutamate receptor activation. Nature 373:612-615.

Ylinen A, Soltész I, Bragin A, Penttonen M, Sik A, Buzsáki G (1995) Intracellular correlates of hippocampal theta rhythm in identified pyramidal cells, granule cells, and basket cells. Hippocampus 5:78-90. 